\title{
Formació per a la prevenció de la violència de gènere a la formació inicial de les persones professionals de l'educació $i$ professorat universitari
}

\author{
Entidad que Financia: Agència de Gestió d'Ajuts Universitaris i de \\ Recerca (Projectes per a la millora de la qualitat docent a les \\ universitats catalanes- MQD2010).
}

Duración: 2011-2012

Aquest projecte de millora de la qualitat docent es basa en la demanda legal, acadèmica i social de que les facultats d'educació, i més en general les universitats, incorporin formació sobre violència de gènere i la seva prevenció, com a factor de qualitat i com a competència dels nous professionals. Per altra banda, es fonamenta en resultats de diverses recerques que han dut a terme en els darrers anys diversos membres de l'equip que presenta la proposta, sobre aquesta temàtica específica.

Dues investigacions pioneres al nostre país ("Violència de gènere en l'àmbit universitari? Realitats, formes i superació", AGAUR 2006-2007; "Violencia de género en las universidades españolas" Plan Nacional I+D+I - Instituto de la Mujer 20052008), coordinades per la Dra. Rosa Valls (membre de l'equip MQD) varen recollir, a més de dades sobre la violència de gènere en les nostres universitats, les mesures que emprenien les universitats millor situades en els rànquings internacionals, en matèria de prevenció de violència de gènere, assetjament sexual dins de l'àmbit universitari, etc. Entre altres, apareixia la formació tant de cara als estudiants com de cara al professorat de les diferents facultats, en qüestions com identificació i prevenció de violencia de gènere, assetjament sexual dins l'àmbit universitari, etc. Un dels resultats pertinents a destacar és que en l'enquesta aplicada a més de 1000 estudiants de diferents universitats espanyoles en el marc de la investigació Violencia de género en las universidades españolas (Valls, 2006-2008) va reflectir que el 86\% de l'estudiantat considerava necessari treballar el tema de la violència de gènere en alguna assignatura de la carrera o en algun debat, com xerrades, seminaris, etc. 
Dues altres investigacions ("La formació per a la prevenció de la violència de gènere a la formació inicial de les persones professionals de l'educació", AGAUR, 2008-2009; i "Incidencia de la Ley integral contra la violencia de género y la formación inicial del profesorado", Plan Nacional I+D+I, 2008 - 2010 - aquesta darrera dirigida per la Dra. Puigvert) han posat de manifest que les facultats d'educació a nivell de Catalunya i d'Espanya, fins ara, no han incorporat de manera sistemàtica i en matèries obligatòries aquest tipus de contingut, malgrat estar regulades per les lleis espanyola i catalana de violència de gènere: la Llei 5/2008, de 24 d'abril, sobre el dret de les dones a erradicar la violència masclista, estableix la necessitat d'incloure en la formació inicial i contínua dels i les professionals de l'educació, formació obligatòria específica sobre prevenció i detecció precoç de la violència familiar, especialment contra les dones i els seus fills i filles (articles 15, 16 i 18). També la Ley Orgánica 1/2004, de Medidas de Protección Integral contra la Violencia de Género, estableix al seu Article 7 "Formación inicial y permanente del profesorado", que "las Administraciones educativas adoptarán las medidas necesarias para que en los planes de formación inicial y permanente del profesorado se incluya una formación específica en materia de igualdad, con el fin de asegurar que adquieren los conocimientos y las técnicas necesarias que les habiliten para: (...) c) La detección precoz de la violencia en el ámbito familiar, especialmente sobre la mujer y los hijos e hijas".

La manca de preparació de mestres i professionals de l'educació té evidents conseqüències: les recerques assenyalen que existeix una correlació alta entre el maltractament a les dones en l'àmbit domèstic i el maltractament infantil (Pulido i Gupta, 2002). És a dir, a les llars on les dones són víctimes de violència, és molt probable que també ho siguin els seus fills i filles. Tot i això, s'observa que malgrat el professorat passa més hores amb els nens i nenes que altres professionals (treballadors/es socials, metges, etc.) identifica i denuncia menys casos d'abús sexual o altres tipus de violència domèstica (Goldman, 2007).

Per aquest motiu, la Plataforma contra les Violències de Gènere, formada per més de 830 entitats i organitzacions molt plurals, ha impulsat una campanya de sensibilització i recollida de firmes titulada "Erradiquem la violència de gènere formant a les persones professionals de l'educació".

El moment actual, de progressiu desplegament curricular en el marc del desenvolupament de l'Espai Europeu d'Educació Superior (EEES), que comporta, entre altres mesures, la implantació dels nous graus, hauria de servir per garantir aquesta demanda legal, científica i social. La proposta de qualitat docent que es presenta pretén incidir sobre els buits i necessitats d'incorporar la formació en prevenció, detecció i actuacions sobre la violència de gènere en la formació inicial dels professionals de l'educació (mestres de primària i infantil, professorat de secundària, educadors/es socials, pedagogs/es) així com del propi professorat universitari.

Es tracta d'una situació compartida en les diferents universitats catalanes, i per aquest motiu es compta amb un equip interuniversitari. 
La finalitat d'aquest projecte de millora de la qualitat docent consisteix en elaborar i pilotar una proposta de continguts i activitats d'aprenentatge per a ser implementades en els graus i màsters de formació de professionals de l'educació així com, també, per a professorat universitari de totes les titulacions. Basant-nos, en els dos casos, en actuacions i iniciatives dutes a terme en universitats de prestigi internacional.

\section{Referències bibliogràfiques:}

Goldman, J. D. G. (2007) Primary School Students-Teacher's Knowledge and Understandings of Child Sexual Abuse and its Mandatory Reporting. International Journal of Educational Research, 46 (6), pp. 368 - 381.

Ley Orgánica 1/2004, de 28 de diciembre, de Medidas de Protección Integral contra la Violencia de Género.

LLEI 5/2008, de 24 d'abril, del dret de les dones a eradicar la violència masclista.

Plataforma Unitaria Contra las Violencias de Género. http://www.violenciadegenere.org/

Puigvert, L. (2008-2010). Incidencia de la Ley Integral contra la Violencia de Género en la formación inicial del profesorado. Plan Nacional I+D (2004-2007). Ministerio de Igualdad. Instituto de la Mujer

Pulido, M; Gupta, D. (2002) Protecting the child and the family: integrating domestic violence screening into a child advocacy center. Violence against women, 8, pp. 917933.

Valls, R. (2006-2008). Violencia de género en las universidades españolas. Plan Nacional I+D (2004-2007).

\section{Investigadors/es:}

\section{Investigadora principal}

Dra. Lídia Puigvert i Mallart, Departament de Teoria Sociològica, Filofia del Dret i Metodologia de les Ciències Socials, Universitat de Barcelona

\section{Investigadors/es de I'URV:}

Dra. Carme Garcia Yeste, Departament de Pedagogia, Universitat Rovira i Virgili.

Dr. Aitor Gómez González, Departament de Pedagogia, Universitat Rovira i Virgili. 


\section{Altres investigadors/es:}

Dra. Marta Capllonch, Departament de Didàctica de l'expressió musical i corporal, Universitat de Barcelona.

Dra. Rosa Valls i Carol, Departament de Teoria i Història de l'Educació, Universitat de Barcelona.

Gregori Siles Molina, Departament de Teoria i Història de I'Educació, Universitat de Barcelona.

Dr. Javier Díez Palomar, Departament de Didàctica de la matemàtica i de les ciències experimentals, Universitat Autònoma de Barcelona.

Dra. Ainhoa Flecha, Departament de Sociologia, Universitat Autònoma de Barcelona.

Dra. Teresa Sordé Martí, Departament de Sociologia, Universitat Autònoma de Barcelona.

Dra. Elena Duque Sánchez, Departament de Pedagogia, Universitat de Girona.

Dra. Patrícia Melgar Alcantud, Departament de Pedagogia, Universitat de Girona.

Dra. Montserrat Martín Horcajo, Departament de Ciències i Ciències Socials, Universitat de Vic. 